\title{
A AMÉRICA LATINA COMO DESTINO DOS IMIGRANTES: BRASIL E ARGENTINA (1870-1930)
}

\author{
LATIN AMERICA AS A DESTINATION TO IMMIGRANTS: \\ BRAZIL AND ARGENTINA (1870-1930)
}

\author{
André Luiz Lanza $a^{(*)}$ \\ Universidade de São Paulo, São Paulo (SP), Brasil \\ Maria Lucia Lamounier ${ }^{(* *)}$ \\ Universidade de São Paulo, São Paulo (SP), Brasil
}

Resumo: O presente artigo analisa comparativamente a imigração para o Brasil e Argentina entre 1870 e 1930, apresentando dados sobre o fluxo migratório e motivações que levaram os estrangeiros a escolher os dois países como destino. Para a confecção do trabalho, colhemos dados de censos, relatórios ministeriais e anuários estatísticos além da bibliografia pertinente. Os imigrantes representavam a solução para a falta de braços para as lavouras e o agente modernizador das sociedades; os fluxos migratórios estavam relacionados com o desempenho econômico dos dois países. No Brasil, a imigração subsidiada teve grande importância; na Argentina, prevaleceu a imigração espontânea.

Palavras-chave: Imigração; Brasil; Argentina.

Abstract: The present paper analyzes comparatively immigration to Brazil and Argentina between 1870 and 1930, presenting data related to the migration flow and the motivations that led foreigners to choose both countries as their destination. To the sweet of this paper, data were collected from censuses, ministerial reports and statistical yearbooks besides the pertinent bibliography. Immigrants represented the solution to the lack of arms to the harvests and the agent that would come to modernize their societies; the migration flows were related to the economic performance of both countries. In Brazil, subsided migration had great importance; in Argentina, spontaneous migration prevailed.

Key-words: Immigration; Brazil; Argentina.

(*) Mestre pelo Programa Interunidades em Integração da América Latina (PROLAM/USP). E-mail:<a_lanza89@hotmail. com>.

(**) Doutora, Professora Associada da Faculdade de Economia, Administração e Contabilidade de da Universidade de São Paulo (Campus Ribeirão Preto); Professora do Programa Interunidades em Integração da América Latina, da Universidade de São Paulo.E-mail: <lucialamounier@fearp.usp.br>. Recebido em: 15.02.2015; aceito em: 29.06.2015. 


\section{INTRODUÇÃO}

Quando se estuda o período entre 1870 e 1930, diversos temas emergem com frequência na literatura relevante para a América Latina. O começo do desenvolvimento econômico com a expansão das economias primárias voltadas para o mercado externo, os países latino-americanos na rota internacional do comércio, o desenvolvimento da infraestrutura, a urbanização, as mudanças políticas e sociais diversas e a chegada massiva de imigrantes formam parte dos acontecimentos que marcaram o período. A América Latina foi um importante destino para os emigrantes no período das grandes migrações. O período foi marcado por grandes transformações sociais e econômicas, não só na região como no mundo como um todo que, em maior ou menor grau, influenciaram na vinda de estrangeiros para o continente.

No presente artigo, nos propomos a fazer uma análise da imigração para o Brasil e para a Argentina no período mencionado, apresentando dados sobre o fluxo migratório e as motivações que levaram os estrangeiros a escolher os dois países como destino. Ambos foram os destinos mais recorrentes dos imigrantes e ambos apresentaram um desenvolvimento econômico-social similar durante esses sessenta anos entre o final do século XIX e começo do século XX.

O trabalho encontra-se dividido em três seções, além desta introdução e das considerações finais. A primeira seção apresenta um panorama geral da imigração para a América Latina, dando destaque para Brasil e Argentina. A segunda seção analisa a imigração para o Brasil e, mais especificamente, para o estado de São Paulo, principal destino dos estrangeiros dentro do país, buscando identificar o que motivou os estrangeiros a escolherem o Brasil como seu destino final. A terceira seção explora o tema da imigração na Argentina, analisando o que pode ter levado os imigrantes a se dirigirem ao país platino. Para a confecção deste trabalho, além da bibliografia levantada, fizemos uso de Relatórios da Secretaria da Agricultura, Comércio e Obras Públicas do Estado de São Paulo (RSASP), Censos Generales de la Ciudad de Buenos Aires (CGCBA) e anuários estatísticos relevantes.

\section{A IMIGRAÇÃO PARA A AMÉRICA LATINA: UM PANORAMA}

O início do século XIX e primeiras décadas do século XX foram marcados por um imenso deslocamento populacional entre o Velho e o Novo Continente. A cifra exata da quantidade de imigrantes que partiram da Europa com destino às Américas é incerta ${ }^{(1)}$; no entanto, estima-se que entre 42 e 60 milhões de europeus deixaram o continente nesse período, impulsionados por diversos fatores como a melhoria nos meios de transporte e comunicação no século XIX, à busca por melhores condições de vida, oportunidades

(1) Cifras diversas foram apresentadas por vários autores na tentativa de estimar a quantidade total de emigrantes que deixaram a Europa no período. Essas variações ocorrem devido a discrepâncias diversas nos registros das partidas nos países de origem e das entradas nos países de destino. A definição de imigrante nos registros oficiais e o fenômeno da re-emigração entre os destinos e também o fenômeno da migração temporária. Ver por exemplo Rosoli (1992); Klein (2000); Rapoport (2000); Sanchez-Alonso (2007); Gonçalves (2008). 
de emprego e como alternativa à realidade existente nos países de origem. Muitos imigrantes partiam com o ideal de se tornarem proprietários de terra na América; muitos em busca de trabalho assalariado, fosse este permanente ou temporário; e outros partiam fugidos de perseguições religiosas ou guerras.

Segundo Klein (2000, p. 13), a questão básica que envolve o fenômeno da migração está no "peso dos fatores de expulsão ou de atração e a maneira como se equilibram". Para o autor, as condições econômicas constituem o fator de expulsão mais importante, na medida em que afetam diretamente a sobrevivência das famílias. Ainda, segundo o autor, três fatores combinados originaram as grandes migrações europeias nos séculos XIX e XX, época em que chegaram ao Novo Mundo mais de dois terços dos imigrantes. O autor destaca o acesso à terra para sustento próprio, a variação da capacidade produtiva da terra e o número de membros de uma mesma família que precisa ser mantido por um mesmo lote de terra (KLEIN, 2000, p. 12-13).

O crescimento exponencial da população do continente europeu, a partir do século XVIII, aliado à queda progressiva da mortalidade (fenômeno conhecido como "transição demográfica"), com o tempo, passou a exercer pressão sobre o setor agrícola dos países europeus. Essas mudanças dificultaram o acesso à terra pelas populações camponesas, aumentando a quantidade de pessoas a serem mantidas com a produção de um mesmo lote de terra. O número de minifúndios diminuía enquanto o de latifúndios aumentava com rapidez. Os camponeses, que anteriormente viviam numa agricultura de subsistência, se viram obrigadas a trabalhar para outros proprietários de terras (KLEIN, 2000, p. 14-16).

A terra deixava então de ser o meio de vida tradicional do mundo rural europeu, baseado na produção camponesa, e passava a ter uma nova função como fator de produção e fonte de capital, destinada à produção em larga escala (GONÇALVES, 2008, p. 20). Como afirma o autor, "no momento em que os campos europeus entravam em fase acelerada de desarticulação, a América aglutinou a gigantesca dilatação do mercado de trabalho, apresentando-se como imenso território de reserva para numerosos e famélicos contingentes do Velho Mundo" (GONÇALVES, 2008, p. 21). Com a revolução agrícola e a mecanização da agricultura, muitos perderam seus empregos no meio rural e as dificuldades financeiras atingiram grande número dos trabalhadores rurais europeus, expulsando-os para o meio urbano. As cidades eram vistas como alternativas à imigração rural e a habilidade das cidades em absorver esse excedente de população rural determinava a taxa de imigração.

Isso implicava que, em um cenário onde todos os demais fatores permaneciam constantes, quanto mais alto o grau de urbanização e industrialização, menor a taxa de imigração. Outra implicação residia numa queda na taxa de emigração caso a taxa de urbanização e industrialização aumentassem (BAINES, 1994, p. 537). Petrone (1997) tem visão semelhante, afirmando que "as grandes migrações transoceânicas dos séculos XIX e $X X$ constituem (...) um aspecto do movimento demográfico da Europa em que a urbanização e a industrialização desempenham papel relevante" (PETRONE, 1997, p. 95).

Enquanto na Europa a terra era cara e a mão de obra barata, na América, ocorria o inverso: havia terra em abundância e escassez de mão de obra. Klein (2000, p. 22) delega à possibilidade de aquisição de terras um grande peso como fator de atração de imigrantes 
para as Américas. Segundo Rapoport (2000), no geral, há certo consenso entre os autores de que os imigrantes trabalhadores se dirigiam para os destinos cuja quantidade de recursos oferecidos era maior que em suas pátrias. A terra abundantemente disponível, a agricultura de exportação em ascensão e a escassez de mão de obra para trabalhar em atividades relacionadas ao setor aliados aos salários mais altos em comparação à Europa tornaram-se o chamariz de imigrantes para os países da América Latina.

Segundo Sanchez-Alonso (2007, p. 398), até o último quartel do século XIX, a instabilidade política das novas repúblicas latino-americanas, a baixa demanda por trabalho livre na maioria dos países que possuíam uma grande população ou faziam uso do trabalho escravo, alto custo das passagens transatlânticas, clima e geografia desfavoráveis do interior dos países, além das características políticas e culturais não atrativas ajudam a explicar o porquê a América Latina permanecia como um destino marginalizado para os imigrantes perante os Estados Unidos.

Nas últimas décadas do século XIX, esse cenário mudou. As mudanças tecnológicas no final do século XIX foram importantes fatores no fluxo migratório internacional. A substituição dos barcos a vela pelo transporte a vapor, a instalação de cabos telegráficos transatlânticos e o surgimento e expansão das redes ferroviárias durante a segunda metade do século XIX tornaram os transportes e as comunicações entre América e Europa mais rápidos, eficientes e com menor custo. Klein (2000) afirma que "após 1870 os fluxos migratórios e as condições econômicas na América estavam estreitamente relacionadas. Informações sobre as condições de emprego, em especial, estavam agora prontamente disponiveis em poucas semanas, nos principais países europeus de emigração" (KLEIN, 2000, p. 23).

Novas tecnologias permitiam a exportação de produtos perecíveis a longas distâncias. Tais mudanças levaram os países da América Latina às rotas do comércio mundial. Não só a mobilidade de capital se tornou possível, mas, também, ocorria com maior frequência, a mobilidade do fator de produção trabalho entre os continentes. Além das mudanças tecnológicas, depois de 1870 com a estabilidade política e, desde as décadas de 1850 e 1860, com o crescimento das políticas visando à atração de imigrantes estrangeiros, a América Latina passou a ter mais visibilidade na rota mundial de imigração. Mais de 13 milhões de imigrantes entraram no continente entre 1870 e 1930, sendo que 90\% desse total tiveram como destino a Argentina, o Brasil, o Uruguai e Cuba (SANCHEZ-ALONSO, 2007, p. 398-399).

Rosoli (1992) afirma que, até a Primeira Guerra Mundial, 11 milhões se dirigiram para a América Latina dos quais 38\% eram italianos, $28 \%$ espanhóis, $11 \%$ portugueses e 3\% franceses e alemães. Desses 11 milhões, 46\% se destinaram à Argentina, 33\% ao Brasil, 14\% foram para Cuba e 3\% para o México (ROSOLI, 1992, p. 03).

Sanchez-Alonso (2007) afirma que quase todos os governos latino-americanos tentaram de alguma forma atrair trabalhadores estrangeiros, buscando prevenirem-se contra uma possível falta de mão de obra em setores específicos das economias nacionais. Alguns governos acreditavam também que a imigração de "europeus culturalmente superiores" contribuiria para a modernização econômica e social de seus países (SANCHEZ-ALONSO, 2007, p. 398). 
Brasil e Argentina são os melhores exemplos da influência dessas mudanças em suas economias e sociedades (CONDE, 1968, p. 71-72; KLEIN, 2000, p. 23). Até 1870, ambos os países eram caracterizados por amplos vazios populacionais e população escassa e concentrada no litoral. Durante todo o século XIX, a necessidade de povoar territórios e encontrar mão de obra para sustentar o desenvolvimento da agricultura agroexportadora norteou os debates governamentais sobre o fomento da imigração nos dois países.

Além de ser uma solução para a falta de braços nas lavouras e para o povoamento de territórios, nos dois países, a imigração era vista como o caminho para o progresso, para a modernização da sociedade e para o branqueamento da população. A partir de 1870 até 1930, os dois países foram os que mais receberam imigrantes na América Latina. Nesse período, a política de subsídios, custeando as passagens transatlânticas, hospedagem e colocação nas fazendas de café, foi implantada com sucesso no estado de São Paulo. Na Argentina, as políticas liberais de atração de imigrantes e os altos salários pagos nas épocas de colheitas do trigo e milho também tiveram êxito em atrair estrangeiros. Os dois países juntos receberam quase $80 \%$ do total dos que imigraram para a América Latina até 1930.

Entre 1870 e 1930, mais de 4.100.000 estrangeiros entraram no Brasil no período; cerca de 6.200.000 imigrantes se dirigiram para a Argentina. Um grande número desses imigrantes se estabeleceu no estado de São Paulo e na província de Buenos Aires e tiveram contribuição direta para o crescimento da população, para a ampliação do mercado de trabalho rural e urbano e para o desenvolvimento da urbanização e da industrialização.

\section{A IMIGRAÇÃO NO BRASIL}

No Brasil, as pressões para o fim do tráfico de escravos e a abolição da escravidão ao longo do século XIX, a expansão das fronteiras agrícolas concomitantemente com a expansão das ferrovias, interligando as regiões produtoras com os centros consumidores e exportadores, a expansão cafeeira, dinamizando a economia do país ao longo da segunda metade do século XIX e ganhando força no final do século, e a falta de braços para a lavoura foram fatores que, interligados, culminaram na entrada massiva de imigrantes no país e, principalmente, em São Paulo.

As primeiras ideias sobre a promoção da imigração livre para o Brasil ocorreram logo no início do século XIX, com a formação de núcleos coloniais. No decorrer da primeira metade daquele século, outras políticas foram propostas, visto que os núcleos coloniais não estavam dando os resultados esperados. Em 1850, foram aprovadas as leis sobre o fim do tráfico internacional de escravos e sobre as terras devolutas; esperava-se com isso, melhores resultados nas políticas de imigração. Na mesma década, ocorreram as primeiras experiências com trabalhadores livres em fazendas cafeeiras paulistas, na forma das colônias de parcerias, sem muito sucesso.

O movimento abolicionista das décadas seguintes pôs em evidência a urgência em se conseguir um substituto para os escravos nas lavouras. Nos anos 1870, o governo de São Paulo passou a intervir mais ativamente no fomento à imigração. Na década de 1880 , uma política imigrantista foi implantada e, em 1886, tem-se o começo da imigração 
subsidiada para São Paulo. A política de subsídios foi responsável por grande parte das entradas de imigrantes até 1930.

Para Fausto (1986), a imigração para o Brasil dependeu de fatores como as condições sociais e econômicas no país de origem, a conjuntura internacional e do estado da economia brasileira, principalmente, da economia cafeeira. O período de 1890 a 1900 foi o de maior entrada de imigrantes tanto no Brasil quanto em São Paulo. A crise econômica e a recessão na Itália entre 1885 e 1895 estimularam a emigração, especipalmente dos povos do norte.

A Argentina e os Estados Unidos, dois destinos mais procurados pelos imigrantes, estavam em recessão desde o começo da década de 1890. Nessa mesma época, a rápida expansão da produção cafeeira, o aumento da demanda por mão de obra e o temor das consequências da extinção recente da escravidão estimularam as políticas de atração de imigrantes. Os subsídios oferecidos aos estrangeiros em forma de passagens gratuitas atraíram cerca de $80 \%$ dos imigrantes que entraram em São Paulo no período.

Na década de 1890, entraram em São Paulo 735.076 imigrantes dos quais 596.004 eram subsidiados. Essa década representou o ápice da imigração subsidiada. Durante todo o período analisado, entraram no estado 2.561 .981 imigrantes, sendo que 1.151.389 se beneficiaram dos subsídios oferecidos pelo governo paulista. A partir do início do século, a imigração espontânea ganha força e passa a predominar sobre a subsidiada. Isso pode ser explicado pelos decretos nos países europeus proibindo a imigração subsidiada para São Paulo, pela melhor organização dos serviços de imigração em São Paulo e por uma melhor propaganda no exterior para a atração dos estrangeiros (LANZA, 2015, p. 88).

Segundo Petrone (1997, p. 108), os incentivos econômicos nas fazendas cafeeiras e no meio urbano funcionavam como fatores de atração para os imigrantes espontâneos. A autora afirma também que boa parte desses imigrantes eram formados por artesãos ou trabalhadores industriais que desejavam estabelecer-se no meio urbano. Holloway (1984, p. 84) também afirma que é bem provável que essa massa de imigrantes espontâneos tenha se dirigido para o crescente mercado de trabalho na zona urbana.

O final dos anos 1890, e o começo dos anos 1900 foram marcados pela superprodução cafeeira e, crise no setor, culminando no Convênio de Taubaté em 1902, que limitou a plantação de novos pés de café. No mesmo ano, na Itália, o Decreto de Prinetti proibiu a imigração subsidiada para o Brasil, em virtude dos casos de maus-tratos e péssimas condições de vida dos imigrantes nas fazendas de café de São Paulo, o que levou a uma queda na entrada de imigrantes no país e a saldos negativos na imigração dos anos seguintes. A recuperação desse fluxo se deu na segunda metade da década de 1900 e atingiu o apogeu nos anos anteriores à Primeira Guerra Mundial, quando novamente o fluxo se viu interrompido. Nos anos de 1920, o fluxo migratório que se orientou para o país não ocorreu motivado pela economia cafeeira. Conforme observa Fausto (1986), "nas áreas rurais de São Paulo e do sul do país, havia muito mais possibilidades para os pequenos produtores dedicados à produção de alimentos". Além disso, houve uma reorientação no destino dos imigrantes, que agora se dirigiam para as grandes cidades (FAUSTO, 1986, p. 782). 
Para Hall (1979, p. 202), não há dúvida de que as origens da imigração em grande escala estão "intimamente relacionadas à questão da escravidão. Embora frequentemente se diga que a abolição tornou possível a migração em massa, provavelmente a relação oposta está mais próxima da verdade". Apesar de polêmica, a afirmação de Hall destaca o papel da imigração para a transformação das relações de trabalho nas fazendas de café paulista.

A partir de meados da década de 1880, com o agravamento das fugas em massa e ameaças de desordem por parte dos escravos, a política de subsídios do governo provincial paulista apresentou os primeiros resultados. Já, de acordo com Holloway (1984, p. 61), o que impulsionou a imigração para o Brasil e para São Paulo não foram as condições de vida no país de origem - crise econômica ou pressão demográfica - mas sim o fim do sistema escravista no Brasil. Para Stolcke e Hall (1983), a imigração subsidiada permitiu aos cafeicultores abolirem a escravidão sem incômodos e o esquema, aliado à alta dos preços do café, permitiu a expansão do cultivo e da produção (STOLCKE; HALL, 1983, p. 107).

Entre 1870 e 1886, entraram, em média, 24.200 imigrantes no Brasil por ano. Entre 1886, início da imigração subsidiada, até 1894, as entradas médias anuais foram de quase 100.000 estrangeiros. No período de 1895 a 1897 , entraram mais de 145.000 estrangeiros por ano no país. De 1911 a 1913, esses números variaram entre 135.000 e 190.000 imigrantes anuais. Ainda que a década de 1920 tenha apresentado uma nova onda de imigração, principalmente, de 1923 a 1927, apenas o ano de 1926, registrou uma entrada superior a 100.000 imigrantes (LANZA, 2015, p. 82). Dados do Anuário Estatístico do Brasil para o ano de 1936, mostram que de 1886 a 1935 entraram no país um total de 4.012.642 estrangeiros. Desse total, mais de 1,3 milhão eram italianos, 1,1 milhão de portugueses e 578.000 espanhóis, sendo essas três nacionalidades responsáveis por mais de 77\% do total de imigrantes que o Brasil recebeu no período (INE, 1936, p. 76).

Conforme os imigrantes chegavam nas lavouras de café e os problemas com a população escrava aumentavam, os fazendeiros se convenciam da qualidade superior do trabalhador estrangeiro e puderam tranquilamente substituir os escravos pelos imigrantes, principalmente, os italianos. De acordo com Hall (1979, p. 202), estimava-se que cerca de 50.000 escravos eram necessários para a agricultura em São Paulo na década de 1880. Antônio Prado, um dos arquitetos da política paulista de imigração, anunciava no Senado brasileiro em maio de 1887 que entre 60.000 e 70.000 imigrantes já haviam sido colocados nas fazendas cafeeiras até aquela data, afirmando que o limite de absorção dessa mão de obra estava sendo atingido. Ainda, segundo Hall (1979), os fazendeiros receberam com prazer a abolição (HALL, 1979, p. 202).

As pressões exercidas por parte dos cafeicultores perante o governo de São Paulo, diante do temor da falta de braços para as lavouras, fizeram com que fosse instituído o sistema de subsídios de passagens aos imigrantes. Essa subvenção assegurou a entrada contínua de estrangeiros até ao final da década de 1920 ao custear o transporte transatlântico e prover infraestrutura para o recebimento dos estrangeiros.

Até 1886, ano de início do sistema de subsídios paulista, São Paulo havia recebido apenas 53.055 imigrantes. Entre 1872 e 1875, somente 6,26\% do total de imigrantes entrados no Brasil se dirigiram para o Estado de São Paulo. No período seguinte, de 1876 a 1880 , esse percentual foi de 5,35\%. Nos anos de 1881 a 1885 , período imediatamente 
anterior ao começo dos subsídios, a porcentagem de imigrantes entrados em São Paulo já apresentava aumento, correspondendo a $16,28 \%$ do total de entrados no país.

De 1882 a 1886, vieram ao Estado, em média, 6.000 estrangeiros por ano ${ }^{(2)}$. Segundo Vasconcellos (1941, p. 05), depois da Constituição de 1891 ter concedido aos estados a liberdade para legislarem sobre a imigração, de modo a promovê-la levando em conta com as necessidades de cada Estado, o Governo da União, que até então promovia a introdução de estrangeiros em território nacional, deixou de fazê-lo. Depois dos primeiros anos da República, observou-se uma expressiva alteração do fluxo migratório dirigido aos diversos estados. São Paulo, que em 1878 havia recebido apenas 9,2\% dos imigrantes que entraram no país e $17,1 \%$ em 1883, recebeu $67 \%$ do total em 1887 e 84,1\% em 1901. Segundo Vasconcellos (1941):

esse fato é explicável porque entre todas as Províncias foi a de São Paulo a que, no regime imperial, a fim de fazer face à crise do trabalho agrícola provocada pela emancipação progressiva dos escravos, resolveu seguir a experiência realizada pelo Governo Central organizando, com clarividência, os serviços de imigração e promovendo, com os seus próprios recursos, a introdução de imigrantes. Essa política de larga visão deu resultados extraordinariamente compensadores, pois evitou que o Estado sofresse prejuízos com a emancipação total do escravo em 1888 e, depois, concorreu para o seu desenvolvimento vertiginoso na República, quando aumentou o fomento à imigração invertendo, para esse fim, verbas consideráveis (VASCONCELLOS, 1941, p. 05).

\section{Tabela 01 - Entrada de Imigrantes no Brasil e em São Paulo até 1930}

\begin{tabular}{lrrrrr}
\hline Período & $\begin{array}{c}\text { Imigrantes } \\
\text { entrados no } \\
\text { Brasil }\end{array}$ & $\begin{array}{c}\text { Imigrantes } \\
\text { Entrados no } \\
\text { Estado de São } \\
\text { Paulo }\end{array}$ & $\begin{array}{c}\text { Imigrantes } \\
\text { Subsidiados } \\
\text { em São Paulo }\end{array}$ & $\begin{array}{c}\text { Imigrantes } \\
\text { Espontâneos } \\
\text { em São Paulo }\end{array}$ & $\begin{array}{c}\text { Não especifi- } \\
\text { cados em São } \\
\text { Paulo }\end{array}$ \\
Até 1889 & $624.959^{2}$ & 205.608 & 22.886 & 5.007 & 177.715 \\
$1890-1899$ & 1.198 .325 & 735.076 & 596.004 & 139.072 & - \\
$1900-1909$ & 623.405 & 388.708 & 164.384 & 224.324 & - \\
$1910-1919$ & 815.453 & 480.509 & 186.383 & 294.117 & - \\
$1920-1930$ & 909.317 & 752.080 & 181.732 & 530.704 & $\mathbf{1 7 7 . 7 1 5}$
\end{tabular}

Fontes: SÃO PAULO, Secretaria dos Negócios da Agricultura, Indústria e Comércio do Estado de São Paulo. Relatórios, vários anos. LEVY, M. S. F. O papel da migração internacional na evolução da população brasileira (1872-1972). Revista de Saúde Pública, São Paulo, v. 8, complemento, pp. 71-72, 1974(1). Referente aos anos de 1872 a 1889; para São Paulo, começa-se a série em $1827 ;{ }^{(2)}$ Entrada de imigrantes de terceira classe via porto de Santos, outros portos e estradas de ferro.

(2) Os dados apresentados foram retirados de SÃO PAULO, Secretaria dos Negócios da Agricultura, Indústria e Commercio do Estado de São Paulo. Relatórios, vários anos; e Levy (1974, p. 71-72). 
Durante todo o período de vigência da imigração subsidiada, entre os anos de 1886 e 1928, o estado de São Paulo recebeu cerca de 59\% dos estrangeiros que entraram no país, havendo picos como no período de 1901 a 1905 quando quase $70 \%$ deles se dirigiram ao estado. Vasconcellos (1941, p. 6) afirma que a razão pela qual a maior parte da corrente imigratória ter se dirigido a São Paulo foi "o estímulo crescente dado pela administração paulista à introdução de imigrantes" diante do "pequeno interesse demonstrado pelo Governo da União, de 1896 em diante, pelo desenvolvimento da imigração". A Tabela 01 congrega os dados da entrada de imigrantes no Brasil e em São Paulo até 1930.

Os Relatórios da Secretaria da Agricultura, Comércio e Obras Públicas do Estado de São Paulo (RSASP) ${ }^{(3)}$, apresentados pelos Secretários da Agricultura ao Presidente do Estado, para cada ano em que foram publicados, trazem comentários sobre os resultados da imigração. O Relatório apresentado ao Presidente do Estado pelo Secretário da Agricultura, Dr. Theodoro Dias de Carvalho Jr., em 1895, relaciona as baixas entradas daquele ano à suspensão dos embarques em agosto de 1893, por causa do aparecimento da cólera na Hospedaria de São Paulo, e que continuou até o reestabelecimento da paz procedente à Revolta da Armada de 6 de setembro de 1893. Isso levou ao não embarque de imigrantes europeus nos meses de inverno na Europa onde a procura de trabalho por parte dos trabalhadores rurais era maior (RSASP, 1896, p. 36). A imigração apresentou resultados melhores nos anos seguintes, mas as entradas voltaram a cair em 1898 e 1899 . O Relatório de 1898 apontou como causas para essa queda os embaraços criados na Áustria, e na Espanha para a saída de imigrantes e as condições da economia brasileira (RSASP, 1898, p. 45).

A partir de novembro de 1898, a peste bubônica em Santos contribuiu para que as entradas e saídas ocorressem pelo porto do Rio de Janeiro e isso se refletiu nas menores ingressos registrados em 1899, ano desfavorável ao movimento imigratório. A entrada de passageiros foi a menor registrada dos últimos seis anos até aquele momento, assim como a de imigrantes subsidiados. A imigração espontânea por primeira vez excedeu a subsidiada (RSASP, 1899, p. 68-70). O Relatório de 1899 atribui também a diminuição das entradas dos imigrantes subsidiados naqueles últimos dois anos às condições contratuais da imigração e à crise da agricultura no período:

Com efeito, pagando o Estado a passagem somente aos imigrantes agricultores, depois de verificada essa condição na Hospedaria, é bem claro que as dificuldades que assoberbam a lavoura não são propícias para avolumar a vinda de braços para ela, assim como, exigindo a fiscalização rigorosa dos contratos, que sejam glosados as passagens dos imigrantes não agricultores, à medida que as glosas tomam maior vulto os contratantes veem-se obrigados a maiores cautelas para não concederem passagem a imigrantes que, ao embarcarem se dizem agricultores e aqui chegados declaram-se artistas, o que, de certo, obrigando a uma maior seleção por parte dos agentes não pode fazer avultar os embarques (RSASP, 1899, p. 79).

Entre 1901 a 1920, as quantidades de imigrantes que entraram no estado sofreram flutuações. Nessas duas décadas, São Paulo recebeu mais de 820.000 imigrantes vindos do exterior. Em 1901, entraram 70.348 estrangeiros. Nos anos seguintes, as entradas

(3) SÃO PAULO. Secretaria da Agricultura, Commercio e Obras Públicas. Relatório da Agricultura. Referiremo-nos aos diversos relatórios da Secretaria da Agricultura pela sigla RSASP. 
diminuíram, voltando a crescer apenas às vésperas da Primeira Guerra Mundial. Em 1911, chegaram a São Paulo 61.508 estrangeiros. Em 1912, foram 98.640 e 116.640 em 1913. O Relatório apresentado pelo Secretário da Agricultura, Dr. Antônio de Pádua Salles ao Presidente do Estado em 1912, referente aos anos de 1910 e 1911, afirma que o aumento geral da imigração em 1911 deveria ser atribuído, primeiramente à alta do preço do café, que se refletia nas condições econômicas, determinando maior procura nas fazendas e em outros setores do mercado laboral por mão de obra; em segundo lugar, às medidas adotadas pelo governo, aumentando o subsídio às passagens e permitindo a introdução de outros imigrantes além de agricultores (atitude essa tomada visando evitar a saída de braços da lavoura para outros serviços), influenciaram o crescimento da imigração subsidiada (RSASP, 1912, p. 122). Já o Relatório da Secretaria da Agricultura para os anos de 1912-1913 observa que o aumento na entrada de imigrantes nesses anos era em razão do crescimento do setor industrial entre 1911 e 1913; o crescimento da imigração espontânea se devia à grande demanda por operários, sendo que em 1912 entraram no estado 53.613 imigrantes e em 1913, 60.063 espontâneos. A imigração destinada à lavoura também se desenvolveu, tendo recebido 45.334 imigrantes em 1912 e 59.694 em 1913 (RSASP, 1914, p. 178-179).

A Primeira Guerra Mundial não paralisou por completo a vinda dos estrangeiros e, entre os anos de 1914 e 1918, entraram 114.103 imigrantes no estado. No entanto, os relatórios analisados mostravam a preocupação das autoridades com uma possível escassez de braços em virtuda das baixas entradas de imigrantes nesses anos e do aumento da emigração (RSASP, 1918, p. 150-151; RSASP, 1917, p. 110-111). De 1921 a 1930, entraram no estado 486.149 imigrantes, sendo o ano mais representativo desse período o de 1926, quando chegaram a São Paulo 76.796 imigrantes (RSASP, vários anos).

Os italianos representaram o maior grupo de estrangeiros a entrar no país no período estudado e, em sua grande maioria, se dirigiram para o estado de São Paulo. Durante o último quartel do século XIX, a América recebeu mais da metade do total de imigrantes saídos da Itália. Os imigrantes que possuíam mais dinheiro e podendo, assim, pagar sua própria passagem para a América Latina para lá se dirigiam, onde as perspectivas de vida eram melhores, os problemas com a língua eram menores e a adaptação cultural era mais fácil.

Segundo o Klein (1989), o fluxo de imigrantes italianos que se dirigiu para o Brasil e para a Argentina era semelhante, sendo a grande maioria trabalhadores agrícolas. Na década de 1870 e 1880, a Argentina foi a principal receptora. Depois da abolição da escravidão ao final da década de 1880 e o uso de mão de obra subsidiada nas lavouras cafeeiras paulistas, o Brasil "emergiu temporariamente como a principal zona de imigração, apesar do aumento constante da imigração italiana tanto para os Estados Unidos como para a Argentina". Notícias de maus-tratos e péssimas condições de vida fizeram com que o governo italiano, em 1902, proibisse a imigração subsidiada para o Brasil, diminuindo pela metade o fluxo de italianos para o país.

Para o estado de São Paulo, tem-se, nas décadas de 1890 e 1900, o predomínio dos italianos, correspondendo a $58,5 \%$ e $47,48 \%$ do total de imigrantes entrados no estado. No início da segunda metade da década de 1910, as nacionalidades dos imigrantes que 
entravam no estado de São Paulo começaram a se modificar. Os italianos, que vinham mantendo a liderança, foram superados pelos espanhóis nos anos de 1905, 1906 e 1909.

O Relatório da Secretaria da Agricultura de 1905 apresentado ao Presidente do Estado pelo Dr. Carlos Botelho, Secretário da Agricultura já afirmava que a imigração espanhola vinha ganhando impulso e tomando o lugar da italiana que, desde 1902, vinha perdendo representatividade com o fim do pagamento de subsídios a esta nacionalidade. O relatório ainda afirma que:

o desenvolvimento da imigração hespanhola, além de alimentar a corrente de braços indispensáveis à lavoura cafeeira, na medida conveniente, creará novas e mais estreiras relações commerciaes com a Hespanha, facilitando o comercio directo e o aumento das permutas, tendo já sido assignalada a presença neste Estado de viajantes comerciaes hespanhoes, incumbidos de promover a colocação em nossas praças de produtos daquele paíz" (RSASP, 1906, p. 114).

Já, nos anos 1910, os espanhóis passaram a assumir a liderança com 30,30\%, seguidos pelos portugueses com 29,71\% e pelos italianos com 23,70\%. Na década de 1920 , os portugueses correspondiam a $23,27 \%$, os italianos, a $15,3 \%$, os espanhóis, a $13 \%$ e os japoneses, a 11\% das entradas de imigrantes (RSASP, 1929, p. 217).

\section{A IMIGRAÇÃO NA ARGENTINA}

Na Argentina, o início dos debates sobre a promoção da imigração ocorreu nas primeiras décadas do século XIX. A imigração também era vista como a solução para a escassez populacional em determinadas regiões e para a contínua expansão da economia de agroexportação. Além disso, a imigração, principalmente, a europeia, assim como no Brasil, também era vista como parte fundamental do processo de transformação da sociedade argentina em uma sociedade moderna.

Juan Bautista Alberdi afirmava que os imigrantes, por serem portadores de um conjunto de hábitos e valores especiais que, incutidos na população local, levariam à civilização da sociedade e à modernização da Argentina, deveriam mudar o país. A essência de seu pensamento pode ser sintetizada na frase "Gobernar es poblar" que serviu como fonte de inspiração para a Constituição de 1853 (ALBERDI, 1916, p. 15-89).

Para Bartolomé Mitre, Presidente durante o período de 1861-1868, os imigrantes deveriam "convalidar um destino de grandeza, integrando-se ao curso de uma identidade histórico-cultural preexistente" (DEVOTO, 2000, p. 36). No programa de Domingos Faustino Sarmiento, os imigrantes também tinham um papel central de realizarem mudanças na sociedade não somente no sentido de possuírem valores e hábitos superiores, mas também no sentido de servirem como trabalhadores agrícolas (DEVOTO, 2000, p. 35). Para uma revisão detalhada das políticas migratórias argentinas e do pensamento vigente à época sobre o tema, ver dentre outros: Devoto (2000); Sanchez-Alonso (2013); e Lanza (2015, p. 55-73).

A visão dominante era que, para transformar radicalmente a sociedade, era necessário trazer a Europa à América. Somente a partir de meados do século XIX, a imigração 
ganharia força, com a aprovação de uma constituição de cunho liberal em 1853 onde ficou estabelecido que a imigração europeia era uma questão nacional. Os governos que a sucederam promoveram políticas de fomento à imigração.

O extermínio indígena, a ampliação das fronteiras e a promoção da imigração constituíam as principais ações a serem empreendidas pelo poder oficial visando modificar a realidade territorial e populacional da Argentina. Diferenciando-se do Brasil, a Argentina não teve um programa de subsídios bem-sucedido, ainda que tenha havido a tentativa de implantar um no final da década de $1880^{(4)}$. Por mais que tenha havido tentativas de modificar o caráter aberto da política imigração, mediante decretos nas primeiras décadas do século XX, estes não tiveram resultados e a imigração permaneceu um fenômeno contínuo até 1930. A imigração predominante na Argentina foi a imigração espontânea.

As circunstâncias que permitiram a corrente imigratória ocorrida nas últimas décadas do século XIX e começo do século XX na Argentina estavam relacionadas a fatores externos e internos. Na Europa, a crise econômica vivida nas décadas de 1880 e 1890, principalmente, na Itália e na Espanha, impulsionaram a saída de seus cidadãos para os países do Novo Mundo. Na Argentina, o fim da "ameaça indígena", com a Conquista do Deserto pelo General Roca, o fim das guerras civis e a consolidação do governo nacional, estabilizaram a vida política e econômica do país e aliado aos investimentos em infraestrutura e a expansão da agropecuária exportadora tornaram o país atrativo aos imigrantes.

Rapoport (2000, p. 40) afirma que:

a conjunção de ambos fatores, internos e externos, somados a estrutura latifundiária de propriedade de terra (grandes extensões de terra em poucas mãos) e ao predomínio da região do litoral e de suas cidades portuárias, tornam possível compreender o momento, a magnitude e as modalidades do processo de imigração e de seus efeitos sobre o desenvolvimento econômico nacional (RAPOPORT, 2000, p. 40).

Por volta de 1880, já haviam entrado no país cerca de 440 mil europeus. Dado o tamanho relativamente pequeno da população argentina, a imigração teve um grande impacto no em seu crescimento nas décadas seguintes; em 1914, os estrangeiros correspondiam a aproximadamente $30 \%$ da população total do país (KLEIN, 2000, p. 21-22).

Conforme as terras eram postas à disposição pela Conquista do Deserto e da integração realizada pelas ferrovias, dois problemas surgiam na Argentina: a falta de população para colonizar essas novas regiões e a escassez de mão de obra para trabalhá-las. Lattes e Sautu (1978, p. 14-16) afirmam que, entre 1870 e 1930, a demanda por mão de obra, escassa no país, para sustentar a expansão do setor agroexportador, trouxe mi-

(4) O governo argentino tentou, sem sucesso, implementar um programa de subsídios visando reorientar regionalmente o fluxo migratório, graças à predominância de italianos e espanhóis entre os chegados à Argentina e à ideia de que os imigrantes civilizados e capazes de mudar o país seriam os do norte da Europa. O programa tinha o objetivo de conceder 200.000 passagens, excluindo formalmente os italianos, no seu período de vigência entre 1888 e março de 1891. No entanto, essa política conseguiu atrair apenas 134.000 estrangeiros entre 1888 e 1890 , equivalente a um quarto do total das entradas registradas no período, quando o programa chegou ao fim por causa da crise econômica que atingiu a Argentina naquele ano (DEVOTO, 2002, p. 251-254). 
lhares de imigrantes para o país. O nível de salários locais mais altos que nos países de origem serviram de incentivo para a vinda dos imigrantes europeus.

De acordo com Solberg (1982, p. 132), a Argentina promoveu imigração com o intuito de povoar seus espaços vazios e prover a força de trabalho essencial para o desenvolvimento agrícola. O autor sustenta que a chave do sucesso da Argentina em atrair imigrantes residia nas políticas governamentais, aceitando todos os imigrantes europeus sadios independente de sua etnia (SOLBERG, 1982, p. 135).

Os milhões de imigrantes chegados à Argentina entre 1870 e 1930 aspiravam encontrar no meio rural a prosperidade e a liberdade, ambos incertos para os pobres na Europa. Para Galiani e Gerchunoff (2007, p. 125), foi somente com a oferta substancial de mão de obra imigrante que o problema da escassez aguda de trabalho na Argentina foi resolvido. Além disso, o crescimento da força de trabalho promovida pela imigração foi um dos fatores essenciais da expansão da área cultivada na Argentina, que na região dos pampas passou de 5 milhões de hectares em 1895 para 25 milhões em 1930.

A demanda por trabalho era altamente sazonal, segundo os autores. Dois tipos de trabalhadores eram necessários para a agricultura arável nos pampas: o primeiro, eram os de caráter sazonal, que tivessem disposição para o trabalho durante os períodos de alta demanda e o segundo, os para o trabalho durante todo o ano (GALIANI; GERCHUNOFF, 2007, p. 125-127).

Lattes e Lattes (1975) também afirmam que a imigração na Argentina não foi um fenômeno estável ou contínuo ao longo do tempo, tendo as entradas e saídas apresentado intensa variação, marcada por uma alta proporção de retornos. Dentre os retornados, principalmente, entre o final do século XIX e começo do XX, merecem destaque os imigrantes golondrinas - trabalhadores temporários atraídos pelos altos salários pagos nos períodos de maior demanda por mão de obra na agricultura (LATTES; LATTES, 1975, p. 61). A Argentina foi o país que mais recebeu imigrantes na América Latina no período: mais de 6,4 milhões de estrangeiros entraram no país entre 1870 a 1930.

As entradas de imigrantes na Argentina apresentaram variações ao longo do tempo. Durante a segunda metade da década de 1850, as entradas de imigrantes no país platino foram de, em média, 5.000 imigrantes por ano, apresentando crescimento contínuo nas entradas nas décadas seguintes, até atingir, em 1873, o ápice daquela década, 76.332 imigrantes. Entre 1873 e 1876, a deterioração dos preços de exportação, afetando a balança comercial e a balança de pagamentos, agravada pelo déficit das contas públicas, obrigou o governo a ajustar os gastos governamentais, levando a uma crise econômica na Argentina que impactou a entrada de estrangeiros no país. Em 1876, as entradas diminuíram para 30.965 imigrantes, menos da metade dos números registrados em anos anteriores, se recuperando apenas no final da década. A aprovação da Lei Avellaneda em 1876, visando à promoção da imigração, somente apresentou resultados em 1883, ano em que as entradas superaram as cifras registradas em 1873 (LANZA, 2015, p. 98). O Censo da cidade de Buenos Aires para o ano de $1887^{(5)}$ explica as reduções de entradas de imigrantes no país, em alguns anos, como segue:

(5) Referiremo-nos ao Censo General de Población, Edificación, Comercio e Industrias de La Ciudad de Buenos Aires por meio da abreviação "CGCBA". 
El considerable descenso que se observa en la inmigración del año 1871, es debido a la fiebre amarilla que, en aquel tiempo, hizo grandes estragos en la población de Buenos Aires. En el año 1874, sobrevino una grave crisis económica, cuyos efectos se sintieron hasta el año 1878. El decaimiento de la producción en general y una baja pronunciada en todos los valores, acarrearon un descenso notable en la inmigración. En 1880 eran los disturbios políticos que acompañaban la renovación del poder ejecutivo nacional, los que determinaron una merma en la cifra de los inmigrantes. Finalmente, en 1886, fue el cólera la causa de la disminución de la mencionada cifra inmigratoria (CGCBA, 1889, p. 508-509).

A década de 1880, com a expansão da fronteira, Conquista do Deserto e ligação da pampa com o litoral por meio das vias férreas e, assim, comunicando a região agroexportadora com os mercados mundiais, foi marcada pelo aumento nas entradas anuais de estrangeiros. Entre 1880 e 1889, as entradas foram, em média, de 100.000 estrangeiros por ano. Segundo Devoto (2007), tanto as oportunidades oferecidas na zona rural na Argentina quanto a crise em algumas regiões campestres da Europa, contribuíram para o traslado de famílias camponesas que emigravam conjuntamente (DEVOTO, 2007, p. 543).

Segundo o autor, a ampliação das oportunidades ocorreu tanto no campo, acompanhando a expansão cerealífera, quanto nas cidades, seguindo o compasso da construção da infraestrutura urbana, das obras de edificações públicas e privadas e dos sistemas de transportes (DEVOTO, 2007, p. 543-545).

A crise econômica de 1890 refletiu-se na imigração. Entre 1890 e 1898, as entradas declinaram para uma média de 72.000 ao ano. No início do primeiro decênio do século $\mathrm{XX}$, esse número disparou novamente para 231.000 por ano aumentando ainda mais nos anos que antecederam a Primeira Guerra Mundial. Devoto (2007) afirma ter ocorrido nesse período a maior onda de imigração para a Argentina, "condicionada pela continuidade da expansão da fronteira agropecuária e pela expansão industrial que a acompanha a um ritmo ainda maior, como produto de um efeito de encadeamento com o setor rural e do enorme aumento do mercado de consumidores urbanos que o mesmo abastecia" (DEVOTO, 2007, p. 545).

Segundo Hora (2010), entre 1905 e 1913, entraram na Argentina ao redor de 300.000 estrangeiros por ano o que representava uma entrada anual superior a $7 \%$ da população total do país (HORA, 2010, p. 173). As cifras referentes à imigração na Argentina entre 1870 e 1914 mostram os imigrantes notadamente elásticos perante as variações na demanda por trabalho. Os dados disponíveis mostram a influência das crises econômicas vividas pelo país nesse período sobre a imigração. A crise ocorrida no meio dos anos 1870 e a crise de 1890 foram acompanhadas por diminuição nas entradas e aumento nas saídas. De acordo com Bourdé (1977):

a conjuntura econômica argentina impõe o ritmo do movimento da corrente imigratória transoceânica. As fases de expansão - de 1860 a 1873, de 1880 a 1889, de 1903 a 1913 e de 1919 a 1929 - coincidem com os períodos de afluência massiva de imigrantes. Inversamente, as crises cíclicas de 1873, 1880, 1890, 1896, 1901, 1913, as prolongadas recessões de 1890 a 1902, de 1929 a 1939 e as duas guerras mundiais interromperam ou reduziram a corrente. A oferta de empregos no país receptor determina diretamente o fluxo de imigrantes (BOURDÉ, 1977, p. 130). 
A recuperação econômica da Argentina depois do término da Primeira Guerra Mundial marca uma nova etapa no movimento migratório para o país que duraria até a crise dos anos 1930. Devoto (2007) aponta também para a lei de quotas dos Estados Unidos, de 1921 e 1924, restringindo a entrada de imigrantes naquele país, especialmente, para os europeus do leste e do sul, como contribuição para as entradas registradas na década de 1920 na Argentina, principalmente, de judeus e poloneses. Ainda que o país também tenha colocado em prática medidas restritivas à imigração, estas não surtiram efeito. $\mathrm{Na}$ década de 1920, a Argentina recebeu 1.397.415 estrangeiros.

Assim como no caso do Brasil, os italianos formaram o grupo de maior predominância entre os estrangeiros imigrados para a Argentina e também os que se concentraram nas regiões mais dinâmicas e avançadas do país. De acordo com Klein (1989):

\begin{abstract}
Na Argentina, os italianos foram o primeiro grande grupo de imigrantes a chegar e puderam estabelecer normas de integração dos imigrantes. Eles tanto predominavam no grupo de pessoas nascidas no exterior, como constituíam uma minoria substancial da população total (representavam 39\% dos nascidos no exterior e 12\% da população total em 1914). Finalmente, eles estavam concentrados na região costeira, que era o centro tanto da agricultura comercial, como de toda a atividade industrial (KLEIN, 1989, p. 101).
\end{abstract}

Os italianos se destacaram em todo o período e, apenas durante a década de 1910, os espanhóis ocuparam o primeiro lugar, correspondendo a $68 \%$ das entradas. Solberg (1982, p. 149) afirma que milhões de italianos viam a Argentina como a terra prometida, onde os pobres recém-chegados poderiam encontrar a prosperidade e onde a língua não representava uma barreira à assimilação dos imigrantes no mercado de trabalho. Para Klein (1989), a principal motivação para a ida desse grupo de imigrantes para a Argentina era a grande disponibilidade de terras e possibilidade de se tornar agricultor (KLEIN, 1989, p. 104).

\title{
5 CONSIDERAÇÕES FINAIS
}

A literatura revelou muitas semelhanças e também muitas diferenças nos processos de imigração para São Paulo e para Buenos Aires. De acordo com a historiografia, durante todo o século XIX, os dois países buscaram formas de atrair imigrantes com o objetivo de povoar seus interiores e fornecer braços para as lavouras agroexportadoras.

A partir de 1870, mudanças no cenário internacional impulsionaram o desenvolvimento econômico do Brasil e da Argentina, o que teve relação direta com o aumento das entradas de estrangeiros em ambos os países. O aumento da demanda global por matéria-prima levou à inserção do Brasil e da Argentina no comércio internacional, o que, por sua vez, fez com que ambas as economias, especializadas em produtos primários, se expandissem.

No Brasil, o motor da economia agroexportadora era o café, produzido nos estados do Rio de Janeiro, de Minas Gerais e, principalmente, de São Paulo. Na Argentina, o motor estava centrado na produção de cereais e de produtos pecuários, como a carne, o char- 
que e a lã na província de Buenos Aires. Outro fator derivado diretamente da expansão do setor primário foi o aumento da demanda por mão de obra, escassa em ambos os países.

Dentre os imigrantes vindos ao Brasil e a São Paulo, as nacionalidades que mais se destacaram foram os italianos, portugueses e espanhóis que juntas representaram mais de $77 \%$ do total de imigrantes. Os italianos representaram o maior grupo de estrangeiros a entrar no país no período estudado. A crise da mão de obra em São Paulo coincidiu com os anos de crise econômica italiana, tanto no setor rural quanto no urbano, durante a década de 1880 e até meados dos anos 1890. Os que buscavam uma vida melhor viam uma oportunidade de fazer fortuna em São Paulo. Ainda que não fizessem parte dos imigrantes ideais, a partir da segunda metade da década de 1900, a entrada de imigrantes japoneses ganha força, movida pela contínua necessidade de braços para as lavouras.

$\mathrm{Na}$ Argentina, os italianos e os espanhóis foram as nacionalidades que mais se destacaram dentre os imigrantes que chegaram no país. Aproximadamente, 2.900.000 italianos e 2.000.000 de espanhóis entraram na Argentina entre 1857 e 1930. Juntos representaram $76 \%$ do total. Na década de 1920, novas nacionalidades de imigrantes passaram contribuir para o cômputo total das entradas no país platino, como os polacos e judeus russos.

Nota-se que, nos períodos em que a economia argentina ou a brasileira entravam em crise, o fluxo migratório tendia a se direcionar para um ou para o outro país. Quando a Argentina entrou em crise na década de 1890, a imigração para o Brasil ganhou forças, impulsionada pelo fim da imigração e pelo crescimento da produção cafeeira em São Paulo. Na primeira década do século XX, a crise na agricultura, a proibição na Itália da imigração subsidiada para São Paulo e, na Argentina, a recuperação econômica, desenvolvimento industrial e contínua expansão da fronteira agrícola impulsionaram e condicionaram a imigração para o país platino.

\section{BIBLIOGRAFIA}

\subsection{LIVROS E ARTIGOS}

ALBERDI, Juan Bautista. Bases y puntos de partida para la organización política de la República Argentina. Buenos Aires: La Cultura Argentina, 1916.

ARANHA, Bruno Pereira de Lima. Rumo à fronteira de Misiones: o 'Destino Manifesto' argentino (1882-1898). Revista Eletrônica da ANPHLAC, n. 16, pp. 225-248, 2014.

BAINES, Dudley. European labor markets, emigration and internal migration 1850-1913. In: HATTON, Timochy; WILLIAMSON, Jeffrey (Eds.), Migration and the International Labor Market 1850-1939. New York: Routledge, 1994.

BOURDÉ, Guy. Buenos Aires: urbanización e inmigración. Buenos Aires: Huemul, 1977.

CONDE, Roberto Cortés. La Expansión de la Economía Argentina entre 1890 y 1914 y el papel de la inmigración. Cahiers du Monde Hispanique et luso-brésilien, v. 10, n. 10, pp. 67-88, 1968.

DEVOTO, Fernando. Imigração Européia e Identidade Nacional nas Imagens das Elites Argentinas (1850-1914) In: FAUSTO, Boris (org.). Fazer a América. 2 ed. São Paulo: Editora da Universidade de São Paulo, 2000.

DEVOTO, Fernando. Historia de la Inmigración en Argentina. Buenos Aires: Sudamericana, 2002. 
DEVOTO, Fernando. La inmigración de ultramar. In: TORRADO, Suzana (ed.). Población y Bienestar en Argentina del Primero al Segundo Centenario. Una historia social del siglo XX. Buenos Aires: Edhasa, 2007.

FAUSTO, Boris. Brazil: the social and political structure of the First Republic, 1889 -1930. In: BETHELL, Leslie (org.) The Cambridge History of Latin America, 1870-1930, v. 05. Cambridge University Press, 1986.

GALIANI, Sebastián; GERCHUNOFF, Pablo. The labor market. In: PAOLERA, Gerardo della; TAYLOR, Alan. New Economic History of Argentina. Cambridge: Cambridge University Press, 2007.

GONÇALVES, Paulo César. Mercadores de Braços. Riqueza e acumulação na organização da emigração europeia para o Novo Mundo. 2008. 518 p. (Tese de Doutorado). Faculdade de Filosofia, Letras e Ciências Humanas, Universidade de São Paulo, São Paulo.

HALL, Michael. Italianos em São Paulo, 1880-1920. Anais do Museu Paulista. Separata XXX. São Paulo, 1979.

HOLLOWAY, Thomas. Imigrantes para o café: Café e sociedade em São Paulo, 1886-1934. Rio de Janeiro: Paz e Terra, 1984.

HORA, Roy. Historia económica de la Argentina en el siglo XIX. Buenos Aires: Siglo Veintiuno Editores, 2010.

KLEIN, Herbet. A Integração dos imigrantes italianos no Brasil, na Argentina e Estados Unidos. Novos Estudos CEBRAP, n. 25, pp. 95-117, 1989.

KLEIN, Herbet. Migração internacional na história das Américas. In: FAUSTO, Boris (org.). Fazer a América. 2. ed. São Paulo: Editora da Universidade de São Paulo, 2000.

LANZA, André Luiz. Imigrantes no Brasil e na Argentina: Políticas de atração, fluxos, atividades e deslocamentos (São Paulo e Buenos Aires, 1870-1930). 2015. 220 p. (Dissertação de Mestrado). Programa de Pós-graduação em Integração da América Latina, Universidade de São Paulo, São Paulo.

LATTES, Alfredo Enrique.; SAUTU, Ruth. Inmigración, cambio demográfico y desarrollo industrial en la Argentina. Cuadernos del CENEP, Buenos Aires, n. 05, 1978.

LATTES, Zulma Recchini de.; LATTES, Alfredo Enrique. La población de Argentina. Buenos Aires, 1975.

LEVY, Maria Stella Ferreira. O papel da migração internacional na evolução da população brasileira (1872-1972). Revista de Saúde Pública, São Paulo, v. 08, suplemento, pp. 49-90, 1974.

PETRONE, Maria Tereza. Imigração. In: FAUSTO, Boris (org.). O Brasil republicano. Sociedade e instituições (1889-1930). 5. ed. Rio de Janeiro: Bertrand Brasil, v. 02, 1997.

RAPOPORT, Mario et al. Historia económica, política y social de la Argentina, 1880-2000. Buenos Aires: Editorial Macchi, 2000.

ROSOLI, Gianfausto. Un quadro globale della diaspora italiana nelle Americhe. Altreitalie, Turim, n. $08,1992$.

SANCHEZ-ALONSO, Blanca. The other Europeans: immigration into latinamerica and the international labour market (1870-1930). Revista de Historia Económica/Journal of Iberian and Latin American Economic History, v. 25, n. 03, pp. 395-426, 2007.

SOLBERG, Carl. Peopling the Prairies and the Pampas: The Impact of Immigration on Argentine and Canadian Agrarian Development, 1870-1930. Journal of Interamerican Studies and World Affairs, v. 24, n. 02, May 1982, pp. 131-161.

STOLCKE, Verena; HALL, Michael. A introdução do trabalho livre nas fazendas de café de São Paulo. Revista Brasileira de História n. 06, pp. 80-120, 1983. 
VASCONCELLOS, Henrique Doria de. Alguns aspectos da imigração do Brasil. In: Boletim do Serviço de Imigração e Colonização, São Paulo, n. 03, março de 1941.

\subsection{DOCUMENTOS}

BRASIL. INSTITUTO NACIONAL DE ESTATÍSTICA (INE). Anuário Estatístico do Brasil. Ano II 1936. Rio de Janeiro: Tip. do Departamento de Estatística e Publicidade, 1936.

BUENOS AIRES. Censo General de Población, Edificación, Comercio e Industrias de la Ciudad de Buenos Aires. Levantado en los días 17 de agosto, 15 y 30 de setiembre de1887. Buenos Aires: CompañíaSud-Americana de Billetes de Banco, 1889. Disponível em: <https://archive.org/details/ censogeneraldel00censgoog>. Acesso em: 12 set. 2014.

SÃO PAULO. Secretaria da Agricultura, Commercio e Obras Públicas. Relatório apresentado ao Presidente do Estado pelo Secretário da Agricultura Dr. Theodoro Dias de Carvalho Junior em 1895. São Paulo: Typ. a vap. Espíndola, Siqueira \& Comp, 1896.

SÃO PAULO. Secretaria da Agricultura, Commercio e Obras Públicas. Relatório de 1898. São Paulo, 1898.

SÃO PAULO. Secretaria da Agricultura, Commercio e Obras Públicas. Relatório de 1899. São Paulo, 1899.

SÃO PAULO. Secretaria da Agricultura, Commercio e Obras Públicas. Relatório apresentado ao Dr. M. J. de Albuquerque, Presidente do Estado pelo Dr. Antonio de Padua Salles, Secretário da Agricultura. Annos de 1910-1911. São Paulo: Typographia Brasil de Rothschild \& Co., 1912.

SÃO PAULO. Secretaria da Agricultura, Commercio e Obras Públicas. Relatório da Agricultura, 1912-1913. São Paulo, 1914.

SÃO PAULO. Secretaria da Agricultura, Commercio e Obras Públicas. Relatório apresentado ao Exmo. Sr. Dr. Altino Arantes, Presidente de S. Paulo pelo Secretário da Agricultura Commercio e Obras Públicas Candido Nazianzeno Nogueira da Motta, Anno de 1916. São Paulo: Typographia Augusto Siqueira \& Co., 1918.

SÃO PAULO. Secretaria da Agricultura, Commercio e Obras Públicas. Relatório apresentado ao. Dr. Altino Arantes, Presidente de S. Paulo pelo Dr. Candido Nazianzeno Nogueira da Motta Secretário da Agricultura Commercio e Obras Públicas Anno de 1917. São Paulo, 1918.

SÃO PAULO. Secretaria da Agricultura, Commercio e Obras Públicas. Relatório da Agricultura, 1928. Apresentado ao Dr. Júlio Prestes de Albuquerque, Presidente do estado, pelo Dr. Fernando Costa, Secretário da Agricultura. São Paulo, 1928.

SÃO PAULO. Secretaria da Agricultura, Commercio e Obras Públicas. Relatório apresentado ao Dr. Júlio Prestes de Albuquerque, Presidente do estado, pelo Dr. Fernando Costa, Secretário da Agricultura, Indústria e Comércio. Anno de 1929. São Paulo, 1929. 